\title{
George Floyd's and Racism Issue as Political Agenda in U.S Presidential Election as Depicted on Digital Media
}

\author{
Vidya Kusumawardani ${ }^{1, *}$, Dodi Faedlulloh ${ }^{2}$ \\ ${ }^{1,}$ Communication Department, Universitas 17 Agustus 1945 Jakarta \\ ${ }^{2}$ Public Administration Department, Universitas Lampung \\ "Corresponding author. Email: vidya.kusumawardani@uta45jakarta.ac.id
}

\begin{abstract}
George Floyd's death by Minneapolis officer as depicted in both digital media (huffpost.com and cnn.com) during May,25- June,9,2020 has triggered public opinion among U.S Presidential Nominee between Donald Trump and John Biden during U.S Presidential Election in 2020. Media, with its power has put Gorge Floyd's and Racism issue as political agenda to gain public opinion toward the U.S Presidential Nominee in 2020 as depicted on both popular media (huffpostcom and cnn.com) based on themes and news articles. Based on themes, Goerge Floyd and racism have become political agendas in both digital news, where politics issue in huffingtonpost was 77 theme (77\%), and CNN was 68 theme (68\%) from 100 samples in each media. Based on news articles, George Floyd and racism put as political agenda in U.S Presidential Nominee during Presidential Election in 2020 as depicted on both digital media based on each variable: Police brutality towards black people on huffingtonpost was $92 \%$ and CNN was $89 \%$, power abuse toward to black people on huffingtonpost was $55 \%$ and $C N N$ was $59 \%$, U.S systemic racism on huffingtonpost was $68 \%$ and $C N N$ was $61 \%$, Democrats and Republican's view on racism on huffingtonpost was $94 \%$ and CNN was $87 \%$, injustice between the white and the black on huffingtonpost was $84 \%$ and CNN was $82 \%$, Public trust/distrust on American Symbol on huffingtonpost was $41 \%$ and $C N N$ was $45 \%$. Based on themes and articles as depicted on both media, George floyd's death and racism have gained public opinion toward U.S Presidential nominee in U.S Presidential Election 2020.
\end{abstract}

Keywords: George Floyd's, Racism, U.S Presidential Election, Public Opinion

\section{INTRODUCTION}

George Floyd's death by Minneapolis Officer on May, 25, 2020 has triggered public anger not only in accross United States but also around the world. In U.S itself, Public distrust on Donald Trump's leadership as a President when dealing with black people. More than hundred years, black people has treated unfairly by the U.S systemic racism. They have been unjustly treated than the whites. In case of stigmatization, the whites acted like they were suspicious of African- American people, where black man are $73 \%$ versus black women is $59 \%$. In education, people acted as if they are not smart where black men are $61 \%$ versus black women $59 \%$. Been subject to slurs or jokes, black man are 57\% versus black woman are $49 \%$. Been treated unfairly in hiring, pay or promotion, black man $50 \%$ versus black woman are $48 \%$. Black men fear for their personal safety at a rate of $46 \%$, while black women fear for their personal safety at a rate of $40 \%$. People assumed they were racists and prejudiced; black men make up $31 \%$ of the population, whereas black women make up 20\% [1]. African-Americans are treated more unfairly than whites when it comes to interacting with the police and criminal justice, with 84 percent of black adults stating that they usually are treated less fairly than whites when it comes to dealing with the police, compared to 63 percent of white adults. In the Criminal Justice System instance, $87 \%$ of blacks and $61 \%$ of whites believe that the US criminal justice system punishes black people unfairly [1].

Black Americans lived in fear of police officers armed with firearms who watched their every move, attacked black people on the street or even in their homes, and murdered them for the slightest apparent provocation [2]. Although whites account for half of 
those shot and killed by police, African-Americans are shot disproportionately. They make up less than $13 \%$ of the population in the United States, yet are slain by police at a rate more than double that of White Americans. Hispanic Americans are also disproportionately killed by police [3]. For decades, several educators have believed that bigotry, prejudice, and stigmatization of black people were sparked by an overwhelming fear of the white group toward the immigrant group known as African Americans, a condition known as Xenophobhia. Additionally, media plays a significant part in our daily lives, infiltrating our perceptions and comprehension with messages that have an effect on our belief and value systems through their news. In this scenario, the media plays a critical role in shaping our attitudes toward black people.

Xenophobia is defined as "attitudes, beliefs, and actions that reject, exclude, and frequently dehumanize individuals based on their perceived status as outsiders or foreigners to the community, society, or national identity." Additionally, "xenophobia attacks persons who are foreigners in a given community, frequently independent of their physical qualities or contrasts with indigenous people. Xenophobia is commonly associated with a belief in a hierarchical world order, in which one's own nation-state is considered superior to others. It is "a complex and multi-causal phenomenon that is frequently connected with periods of economic and political upheaval [4].

Bias, disempowerment, and discrimination against people of color have long been a problem in various facets of mainstream media, including television news, entertainment, and advertising. During the year 1939, racial segregation became a contentious issue in the United States [5]. The United States has a history of marginalizing black people, with a large number of black men and boys being discriminated against and underrepresented in various media outlet [6]s. Happer and Philo's (2013) research revealed that media can also shape behavior by legitimizing specific courses of action but also by introducing doubting perplexity into debates [7].

The media has a long history of bias, prejudice, and hostility toward black people. When news coverage of violent crime is compared to arrest rates, blacks are overrepresented as perpetrators but underrepresented in more sympathetic roles such as victim and law enforcement, as noted in Entman and Gross, 2008, p.98, as referenced by Travis L. Dixon and Daniel Linz, 2000 [6].

The Internet and its multiple online channels have evolved into a global platform for creating, disseminating, and reception of global news, opinions, and agendas. As a result, one can anticipate the design of a worldwide news system that serves as the public sphere. As a result, journalism is becoming increasingly focused on global news from a global perspective[8].

In terms of agenda-setting, these shifts necessitate a reimagining of the process. The classic method is based on a stimulus-response model, in which the media can shape the public agenda under particular conditions. This is almost certainly not the case in today's fragmented media landscape[9]. According to some scholars, in the digital age, as Chaffee and Metzger highlighted, "the critical issue for agenda-setting theory will shift from what the media tell people to think about to what people tell the media they want to think about"[10]. In the digital world, the selection of themes for the media agenda is controlled by viewers, readers, or users' preferences [11].

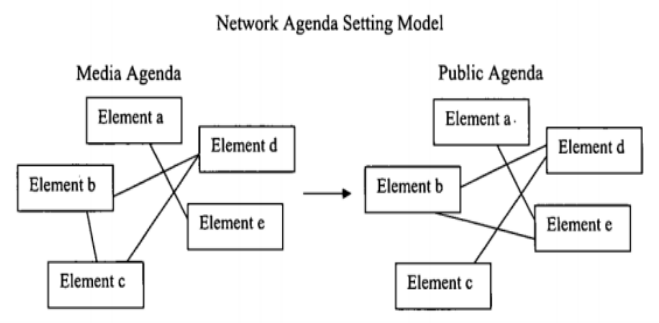

Figure 1 Agenda Setting in Digital Age

This method demonstrates that issues and objects can migrate between agendas not just singly (separately) but also concurrently, and that groups and bloggers should be viewed as mediators between the media and public agendas, fulfilling the previously indicated role of early recognizers[11].

According to Chadwick and Jungherr et al., the internet and social media have generated new "hybrid media systems," expanding the number and types of actors with the power to impact political discourse and agenda setting[12].

According to Kolbitsch \& Maurer, the internet has presented the public with an abundance of information and interactive chances to participate in the content development process in a two-way fashion. According to Chafee and Matzger, the internet's interactive communication capabilities and decentralized nature empower individuals whose objectives would not ordinarily be covered by the big mass media. Through sharing ideas and opinions, netizens collectively create their own agenda, determining which topics should be discussed[10].

The Democratic and Republican Parties claim that their policies assist minorities and racial minorities in the United States. Democratic supporters believe that the Democratic party is more concerned with racial and minority issues than the Republican party are. Over $70 \%$ of African Americans believe the Democratic Party "works diligently on matters of concern to black 
people." Latinos and Asian Americans are slightly less likely to believe that the Democratic Party is especially responsive to issues affecting their pan-ethnic group[13]. Racism is a pervasive, complicated, and poorly understood concept necessary for diagnosing American culture and, more specifically, its political dynamics[14]. The United States has mainly stayed isolated from the worldwide conversation about racism for a variety of political reasons. For some years, the United States government refused to accept the Declaration on the Elimination of All Forms of Racial Discrimination[15].

\section{METHOD}

A Content Analysis method utilized for this research. For this research, we conducted only two most popular news website in the United States which is huffpost.com and edition.cnn.com, from May 25-June, 9,2020.The reason for using a content analysis method to identify whether George Floyd's death and racism issue has become political agenda in U.S Presidential Election as depicted on Digital Media. There were 200 themes which derived from huffpost.com and edition.cnn.com regarding to George Floyd's death and racism issue from May, 25-June,9,2020. Two graduates students were chosen as coders to examine the themes and news articles regarding to George Floyd's death as depicted on both digital media. The coders identified the online news articles themes of hufftpost.com and edition.cnn.com during May 25-June, 9,2020 towards to George Floyd's death. The theme are (1) Police Brutality (2) Systemic Racism, (3) Politics Issue (4) Law and Justice, (5) Law Enforcement, (6) Religion Issue, (7) Economic Issue (8) Health Issue,(9) education issue. Meanwhile, George Floyd's and racism as political agenda as depicted in news articles was divided into several variables (1) Presidential Election, (2) Government credibility, (3) Authority (4) Leadership/power abuse, (5)Racial Problem, (6) Culture Wars (7) Public trust/distrust to American Symbols (8) Law Enforcement (9)Presidential Campaign and racism issue (10) Racism and health issue (11) Religion as a political gain (12) Democrats and Republican view on racism (13) Racism and Education issue (14) Racism and Economic issue (15) environment issue/community safety; (16) Justice system in America towards to black people (17) Injustice between the whites and the black (18)Police Brutality.

\section{RESULT AND ANALYSIS}

Based on the data analysis of theme in both huffpost.com and edition.cnn.com during May, 25, 2020-June, 9,2020 regarding George Floyd Death by Minneapolis Police Officer, politics issue becomes the most highlight news in both online media. Politics issue in huffpost.com was 77 theme (77\%) and edition.cnn.com was 68 theme $(68 \%)$. Police brutality issue in huffpost.com was 4 theme (4\%) and edition.cnn.com was 11 theme (11\%). Systmeic Racism issue in huffpost.com was 11 theme (11\%) and edition.cnn.com was 7 theme. Most interested theme/headlines was brought by huffpost.com were: Hundreds Protest George Floyd's Death in Mineeapolis (huffpost.com-May,26,2020); Public Figures Express Outrage and Demand Accountability After George Floyd Killing (huffpost.com- May, 27,2020); Minneapolis Mayor Calls for Charges in George Floyd Death (huffppost.com-May,27,2020); Trump Calls George Floyd Protesters "THUGS" Threatens Violent Intervention in Mineapolis (huffpost.comMay,29,2020); Chris Hayes Turns Donald Trump's Own Campaign Claims Against Him (huffpost.comMay,29,2020); Meanwhile as we can see on edition.cnn.com were: George Floyd's family says four officers involved in his death should be charged with murder (edition.cnn.com-May,27,2020); Trump's a disaster for black voters, but they also need to hold Biden accountable (edition.cnn.com-May, 28,2020); This is not the America I want to pass down to my children (edition.cnn.com-May,29,2020); Trump's slap at Twitter shows his use of power for personal whims (edition.cnn.com-May, 29,2020).

We can deduce that, depending on the theme, political issues significantly influence public ideology. As Happer and Philo note on the article "The Role of the Media in the Construction of Public Belief and Social Change" media has an effect on our views, assumptions, public ideology, and experiences[7]. In his classic book published in 1922, Lippmann discusses how the mass media can set a particular agenda and thereby affect public opinion. In this instance, the media (huffpost.com and edition.cnn.com) framed George Floyd's death between May 25, 2020 and June 9, 2020 as a political issue based on theme.

As Lawrence states, "racism is an overused, complex, and poorly understood concept that is necessary for diagnosing American society and, more specifically, its political dynamics between parties and politicians [14], specifically Republican and Democratic Party nominees Donald Trump and John Biden as United States Presidential Nominees in the 2020 United States Presidential Election.

Based on news articles that indicate that George Floyd's and racism issue as political agenda as depicted on both digital media, the variable of Republican and Democrats view on racism was becoming the most highlight in both digital media with a total of issue of huffpost.com was 94 (94\%) and edition.cnn.com was 87 $(87 \%)$ issues.

Form variable of Republican and Democrats' view on racism as stated in the articles was "Americans deserve a President who will unite us -- instead, however, President Donald Trump continues to spout the politics of social and racial division that helped get him elected in the first place. Unsurprisingly, his 
response to this tragedy is as insidious as it is counterproductive. (edition.cnn.com-June, 2,2020); Massachusetts Gov. Charlie Baker on Monday excoriated President Donald Trump's "bitterness, combativeness and self-interest" as nationwide protests have intensified over the death of George Floyd. The Republican governor made the comments at a press conference when asked about Trump's video teleconference call, in which the President urged state leaders to aggressively target violent protesters (edition.cnn.com-June, 2,2020).

Variable of Police brutality towards black people on huffingtonpost was $92 \%$ and CNN was $89 \%$. Form of racism as a tools of police brutality as mentioned on hufftpost.com were: Cook said they were marching peacefully with about 100 protesters for hours when police started using tear gas and shooting rubber bullets. As they tried to get away, they were pepper sprayed and her son was hit at close range by a rubber bullet, she said. They were both jailed and released on Monday, charged with riot and violating curfew (huffpost.com-June,6,2020); Meanwhile, form of racism as tools pof police brutality as mention on edition.cnn.com was Ortiz and another friend in the car with him were put in zip-tie restraints and forced to wait on a bus for hours before police took them to jail, where he would spend the weekend. It was scary. It was confusing. I felt violated," said Ortiz, a cellist who identifies as a biracial Mexican American. (edition.cnn..com-June, 6,2020);

Variable of power abuse toward to black people on huffingtonpost was $55 \%$, and $\mathrm{CNN}$ was $59 \%$, Form of leadership/power abuse as mentioned in the online platform was "The president has tried to portray the protesters and looters with a broad brush as "radicalleft, bad people," ominously invoking the name "antifa," an umbrella term for leftist militants bound more by belief than organizational structure. Trump tweeted last Sunday that he planned to designate antifa as a terrorist organization (huffpost.com-June, 6,2020); The President, by choosing to incite division rather than to heal it in the wake of George Floyd's killing and by setting federal security forces on protestors, is signaling no limits to his bid to retain power. He is tearing at social scars to revive a presidency humbled by a pandemic and an economic disaster, and he seems set on creating the dystopian fight between order and chaos he has long evoked (edition.cnn.com-June, 3, 2020).

Variable of U.S systemic racism on huffingtonpost was $68 \%$ and $\mathrm{CNN}$ was $61 \%$. Form of systemic racism as mentioned in the news was "However, Floyd's death has deepened the distrust between Minneapolis residents and police, and prompted a continued series of nationwide - and global - protests against racism and police brutality.(huffpost.com-June, 7,2020); Biden is now promising specific legislation to address the lack of racial equality under the law, giving his potential presidency a generational and reforming purpose -- and possibly an issue that could unite the Democratic left fully behind him and lance suspicion over his role in 1990s crime legislation.(edition.cnn.com-June, 3,2020).

Variable of injustice between the white and the black on huffingtonpost was $84 \%$ and $\mathrm{CNN}$ was $82 \%$. Form of Injustice between the whites and the blacks people as mentioned on huffpost.com were was "The unrest and the frustration you're seeing in the killing of Breonna Taylor is just as much of a cumulative effect of years of pain, frustration, anguish and injustice as it is about how horribly devastating this incident has been," said Kentucky state Rep. Charles Booker (D), who is from and represents part of West Louisville.(huffpost.comMay, 25,2020); "Police in America are looting black bodies" during an impassioned, legthy monologue on the death of George Floyd and the nationwide protest (huffpost.com- May,30,2020). The racial disparities that force black families to breathe pollutants from nearby brownfields, oil refineries, and freeways, and the impact on their respiratory system, is exasperating the effects of this pandemic. As is the lack of preventative care and health care access, and neighborhoods tucked in food deserts with little to no access to nutritious options -- factors that lead to elevated rates of high blood pressure and diabetes (edition.cnn.com-May, 29,2020); We see in the news channels, the media about discrimination on the basis of color or religion these days, and then there is killing due to that, and then there are some who even take it as a pride to be able to kill somebody."(edition.cnn.com-May, 29,2020)

Variable of Public trust/distrust on American Symbol on huffingtonpost was $41 \%$ and CNN was $45 \%$. Form of public trust/distrust towards to American symbols was "I'm very enthusiastic that people around the world were galvanized by the horrific murder of George Floyd in saying, 'No, no, no.' And also, I think that people are going to come out to vote. I'm talking about specifically United States of America, people are going to come out and vote and say hell no to Agent Orange," Lee said, using his nickname for Trump. (huffpost.com-June, 9,2020); The director went on to say that the upcoming presidential election could be the most important in the modern world, adding that if Trump is reelected the "world is in peril." (huffpost.com, June, 9,2020); What he did comes off as tone-deaf," said Costi Hinn, a conservative evangelical pastor and author in Arizona. "The word of God is not powerful in a picture. It's powerful when it's opened up. If you really want to leverage the power of God's word, let it be heard. (edition.cnn.com-June, 4, 2020); Many doubt the justice of our country, and with good reason. Black people see the repeated violation of their rights without an urgent and adequate response from American institutions," Bush said. (edition.cnn.comJune, 4,2020); 


\subsection{Xenophobia Triggered Racism Toward African American}

According to themes and news articles, Xenophobia theory indicates that xenophobia will result in racial action against African Americans. The case of Goerge Floyd, who a Minneapolis police officer killed, demonstrates that whites reject African Americans (as inferiors) due to their perception of outsiders or foreigners to the community, society, or national identity.

The rejection of African Americans residing in America is manifested mainly by verbal abuse, physical assault, aggression or unwanted physical contact, occupational discrimination, police abuse or brutality, and denial of service, as described in print and digital media news articles.

Xenophobia toward African American people in America can be fueled by biased, prejudiced, and antiblack media. When news coverage of violent crime is compared to arrest rates, blacks are overrepresented as perpetrators but underrepresented in more sympathetic roles such as victim and law enforcement, as mentioned in Entman and Gross, 2008, p.98, and Travis L. Dixon \& Daniel Linz, 2000[6].

\subsection{Racism Issue and Public Opinion in Digital Age}

Returning to Agenda Setting Theory, agenda setting theory on digital media will shift away from what the media tells people to think about and toward what people tell the media they want to think about."[10] ... the media agenda is set by viewers, readers, or users, not by journalists or publishers [11]. According to the data above, and following Network Agenda Setting Theory, the public establishes racism as a public agenda in order to mobilize public opinion in opposition to American systemic racism toward the black community. In contrast, the media demonstrates racism as a political agenda by basing their headlines and articles on public interest in racism toward Black People. In this case, Darnella Frazier's recording of George Floyd's murder in Minneapolis last year at the age of 17 became a significant piece of evidence against his killer. It sparked global protests for racial justice and police reform. The public demands that the government charges the cop who murdered George Floyd and hold him accountable through judicial proceedings. Nonetheless, this issue will sway public opinion in favor of a system of systematic racism in dealing with the black community.

People distrust American symbol such as law enforcement in America, especially in Trump's era. Discussing politician portrayals in media towards George Floyd's death, Donald Trump's portrayal is not as good as John Biden, Democrat presidential nominee for the 2020 election. As stated in both Huffington Post and CNN (digital news platform), during May, 25-June, 9,2020 , some public reactions are either to Donald Trump or John Biden as the presidential nominee.

Mostly, the American people have no faith in Donald Trump as the President of America. This thought cannot be separated from the action of Donald Trump as a President when dealing with the black community. As stated in both huffington post and $\mathrm{CNN}$ :

"The president has tried to portray the protesters and looters with a broad brush as "radical-left, bad people," ominously invoking the name "antifa," an umbrella term for leftist militants bound more by belief than organizational structure"(huffpost.com).

"Americans deserve a President who will unite us -instead, however, President Donald Trump continues to spout the politics of social and racial division that helped get him elected in the first place. Unsurprisingly, his response to this tragedy is as insidious as it is counterproductive" (edition.cnn.com).

\section{CONCULSION}

Racism has become a not only social issue but, somehow, it has become a political issue in America toward African-Americans. George Floyd's incident has been a big question among nations regarding to systematic racism in United States. Racism action in America was triggered by excessive fear of the white group againts immigrant group, which is AfricanAmerican, which is called Xenophobia. As stated in the both huffpost.com and edition.cnn.com, the media has portrayed black people as a victim of America's systemic racism by highlighting Democrat and Republican's view on racism, Injustice between the Whites and the Blacks, racial problem, leadership/power abuse, public trust/distrust and yet this issue will lead public opinion towards to each presidential nominee, both John Biden (Democrat) and Donald Trump (Republic) dealing with black community in America.

\section{AUTHORS' CONTRIBUTIONS}

Vidya Kusumawardani: Conceptualization, Formal Analysis, Writing- Original draft, Writing- Reviewing and Editing, Visualization. Dodi Faedlulloh: Formal Analysis, Writing- Reviewing and Editing.

\section{ACKNOWLEDGMENTS}

This study acknowledges to Firman, M.A, Head of Social and Political Studies, Universitas 17 Agustus 1945 Jakarta to support this study.

This study acknowledges to Danang Trijayanto, MA, Head Department of Communication Studies, 
Universitas 17 Agustus 1945 Jakarta to support this study.

\section{REFERENCES}

[1] M. L. \& D. F. Drew Desilver, "10 Things We Know About Race and Policing in the U.S.," Pew Research Center, 2020. .

[2] W. Philimon, "Not just George Floyd: Police Departments Have 400-Year History of Racism,"Usa Today, 2020. .

[3] The Washington Post, "1,019 people have been shot and killed by police in the past year," The Washington Post, New York, United States of America:, 2020.

[4] S. D. Miller, "Xenophobia toward Refugees and Other Forced Migrants," Canada, 2018. [Online]. Available: https://reliefweb.int/sites/reliefweb.int/files/reso urces/WRC Research Paper no.5.pdf.

[5] K. E. Kulaszewicks, "Racism and The Media," Minnesota, USA, 2015.

[6] T. Partnership, "Media Representation and Impact of the Lives of the Black Men and Boys," in Social Science: Literature Review, 2011, p. 22.

[7] G. P. Catherine Happer, "The Role of the Media in the Construction of Public Belief and Social Change," J. Soc. Polit. Psychol., vol. 1, no. 1, pp. 321-336, 2013, doi: https://doi.org/10.5964/jspp.v1i1.96.

[8] Mario Haim and M. Jungblut, 'Politicians' Selfdepiction and Their News Portrayal: Evidence from 28 Countries Using Visual Computational Analysis," Polit. Commun., 2020, doi: https://doi.org/10.1080/10584609.2020.1753869

[9] S. Y. Neumann, R. W., Guggenheim, L., Jang, S. M., \& Bae, "The dynamics of public attention: Agenda-setting theory meets big data.," J. Commun., vol. 64, no. 2, pp. 193-214, 2014, doi: https://doi.org/10.1111/jcom.12088.

[10] Y. Luo, "The Internet and Agenda Setting in China: The Influence of Online Public Opinion on Media Coverage and Government Policy," Int. J. Commun., vol. 8, pp. 1289-1312, 2014, [Online]. Available: https://ijoc.org/index.php/ijoc/article/view/2257/ 1133.

[11] E. Nowak, "Agenda-setting theory and the new media."
[12] A. R. N. Ross, A. Chadwick, and C. Vaccari, "Digital Media and the Proliferation of Public Opinion Cues Online: Biases and Vulnerabilities in the New Attention Economy," 2021.

[13] L. Hajnan Zoltan \& Horrowitz D. Jeremy, "Racial Winners and Losers in American Party Politics." American Political Science Association, 2014, doi: $10.1017 / \mathrm{S} 1537592713003733$.

[14] B. Lawrence., "Racism in Trump's America: reflections on culture, sociology, and the 2016 US presidential election1," Br. J. Sociol., vol. 68, no. S1, pp. 85-103, 2017.

[15] M. Manning, "Structural Racism and American Democracy," in Racism and Public Policy, 2001, pp. 1-19. 